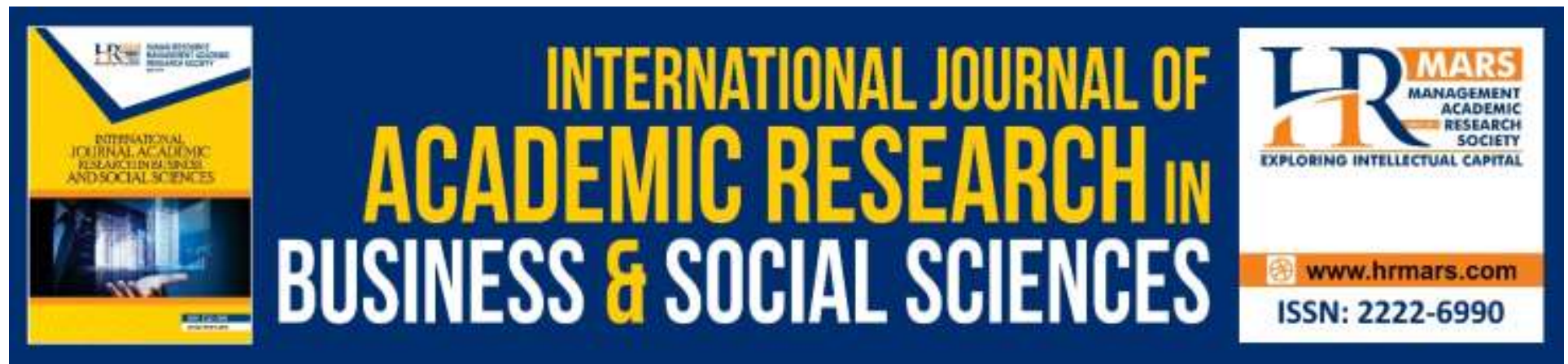

\title{
The Impact of the Social Influence on ICT Adoption: Behavioral Intention as Mediator and Age as Moderator
}

\author{
Arafat A. M. Nassar, Khatijah Othman, Mohd Azmir Bin Mohd Nizah
}

To Link this Article: http://dx.doi.org/10.6007/IJARBSS/v9-i11/6620

DOI: $10.6007 /$ IJARBSS/v9-i11/6620

Received: 16 October 2019, Revised: 01 November 2019, Accepted: 10 November 2019

Published Online: 30 November 2019

In-Text Citation: (Nassar, Othman, \& Nizah, 2019)

To Cite this Article: Nassar, A. A. M., Othman, K., Nizah, M. A. B. M. (2019). The Impact of the Social Influence on ICT Adoption: Behavioral Intention as Mediator and Age as Moderator. International Journal of Academic Research in Business and Social Sciences, 9(11), 963-978.

Copyright: (c) 2019 The Author(s)

Published by Human Resource Management Academic Research Society (www.hrmars.com)

This article is published under the Creative Commons Attribution (CC BY 4.0) license. Anyone may reproduce, distribute, translate and create derivative works of this article (for both commercial and non-commercial purposes), subject to full attribution to the original publication and authors. The full terms of this license may be seen at: http://creativecommons.org/licences/by/4.0/legalcode

Vol. 9, No. 11, 2019, Pg. 963 - 978

Full Terms \& Conditions of access and use can be found at http://hrmars.com/index.php/pages/detail/publication-ethics 


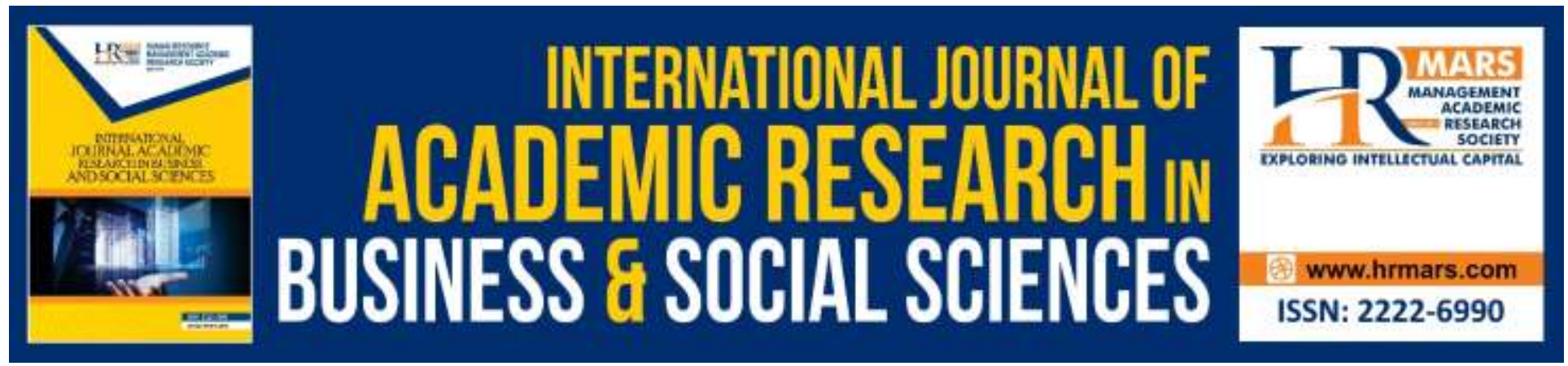

\title{
The Impact of the Social Influence on ICT Adoption: Behavioural Intention as Mediator and Age as Moderator
}

\author{
Arafat A. M. Nassar \\ PhD Candidate, Faculty of Leadership \& Management, Universiti Sains Islam Malaysia, \\ Bandar Baru Nilai, 71800, Negeri Sembilan, Malaysia
}

Khatijah Othman

Faculty of Leadership \& Management, Universiti Sains Islam Malaysia, Bandar Baru Nilai, 71800, Negeri Sembilan, Malaysia

\section{Mohd Azmir Bin Mohd Nizah}

Centre for Core Studies \& Faculty of Leadership \& Management, Universiti Sains Islam Malaysia, Bandar Baru Nilai, 71800, Negeri Sembilan, Malaysia

Email: azmirnizah@usim.edu.my

\begin{abstract}
The tremendous increment of Information and Communication Technology (ICT) adoption in management worldwide helps the organizations to facilitate the services that they provide and improve their performance and productivity. This study aims to investigate the relationship between social influence and ICT adoption. Based on the original Unified Theory of Acceptance and Use of Technology (UTAUT) model, this study examined the mediating role of Behavioral intention and age as a moderating role in the Palestinian Ministry of Higher Education (MOHE). A quantitative approach is employed with self-administered questionnaires were distributed to 343 respondents. Data then were analyzed using the Statistical Package for Social Science (SPSS v-19) and Smart-PLS v3.2.6 to test the research model and hypotheses. The results indicated that Behavioral intention positively mediates between social influence on ICT adoption, while age negatively moderates the relationship between social influence and Behavioral intention. Palestinian MOHE staff does have the high intention of ICT adoption in their daily work and inclined to accept the change. In addition, social influence positively affects the Behavioral intention of ICT adoption in Palestinian MOHE. Results and limitations discussed further.
\end{abstract}


INTERNATIONAL JOURNAL OF ACADEMIC RESEARCH IN BUSINESS AND SOCIAL SCIENCES

Vol. 9, No. 11, November, 2019, E-ISSN: 2222-6990 @ 2019 HRMARS

Keywords: Technological Change, Government Policy, Human Resource Management, ICT Adoption

\section{Introduction}

Information and Communication Technology (ICT) is a technological implication that empowers procedures identified with planning, sparing activity and going of data, mutually with the interrelated strategies, organization, and execution (Lekopanye 2014; Taylor 2015). ICT grants the following, sparing, preparing, assembling and conveying of information. It incorporates new specialized apparatuses like workstations, copied, scaled-down electronic devices, and other media transmission devices, and so on. Obsolete mechanical devices, similar to a recording framework for putting away documents and archives, manual highlight instruments, printing and care drawings, are additionally coordinated into "ICT." (Aleke et al., 2011; Imran and Gregor 2005; Juma et al., 2016; Van et al., 2016).

ICT is regarded as a technology on the global level that allows us to communicate effectively and efficiently and to help us better deal with data. Now, ICT tools are essential for gathering and disseminating knowledge (Adebayo, 2013; Forth \& Mason, 2004; Gallego et al., 2011). In administration and management and research programmes in government institutions, ICT resources are widely adopted. These ICT tools include web portals, intranet and Internet, and customised software. ICT, in particular, the Internet, is currently widely used to interact, coordinate, organise and manage institutions ' human resources. ICT requires many functionalities related to the correct supply of user data (Krishnaveni \& Meenakumari, 2010; Mcgrath, 2014).

Managers regularly deploy ICT tools to convey guidelines and offer engaging corporate training. Managers and instructors have the advantage of this kind of information (Imran \& Gregor, 2005; Chen et al., 2017). Gedwar (2016) stated that ICT software management and administration adaptation benefits in the preparation of announcements for organisations and associations, papers for company and employee meetings; learners to enrol and register; instructors and recruitment personnel. Managers and managers must fully incorporate ICT technologies in decision making, data management and on-line queries to consumers and clients. (Aleke et al., 2011; Attuquayefio et al., 2014). Over time, ICT has changed the way companies work, how partners and how_workers interact among themselves and their customers. ICT affects the interaction between workers and managers or leaders in institutional and organisational management ICT (Dasgupta \& Gupta, 2012).

Many researchers seek to understand the determinants of users' adoption of ICT by studying the factors that encourage ICT adoption to maximise the benefits which may result from implementing ICT, as well as understanding the factors that determine a user's behavioral intention to use ICT. Studies explained that behavioral intention is an individual's subjective possibility of performing a specified behavior, and this is the major contributing factor to actual usage behavior (Ajzen, 1985; Lee, 2009). The perspective on technology adoption is aligned with the user initial intention to use a particular technology. 
United Nations' reports highlight the need for further improvement in the demand side and growing take-up of ICT in developing countries. Moreover, the governmental institutions are not limited to the technical components only, but they also include the social influence in this regard. Taiwo and Downe (2013) mentioned that social influence might affect the administrative staff of the ICT through the influence of colleagues and senior management, as they motivate administrative staff to utilize the ICT by explaining the benefit and the importance to use ICT before and during the use of the particular ICT. Inaddition, Social influence is affecting the plan of users to use ICT if other users perceive the importance of ICT to be influential to their decision in order to adopt ICT.

According to such recommendations, local researchers and the published data of the ministries showed success and failure in the implementation of ICT projects (Ayyash, Ahmad, \& Singh, 2013; Shat\& Amin, 2016). The researcher selected the MOHE for several reasons, firstly due to the significance it differentiates from other countries as an unstable political, economic and security environment under occupation and siege, it is rare to find such a situation in the rest of the world. Secondly, MOHE is working hard to create skilled Palestinian citizens, who can perform work efficiently and effectively, with human resources in the education sector. In the daily operations of ICT applications tools, management personnel in MOHE can also adopt several different kinds of ICT hardware and software tools faster and more accurately.

This study aims to study adoption of ICT administrative staff and the social influence construct which is measured by the perception of how peers affect administrative staff use and adoption of ICT tools. Also, Social influence could be moderated age, as younger administrative staff would be more likely to copy the behavior of others.

\section{Theoretical Background}

This study adopted the Unified Theory of Acceptance and Use of Technology (UTAUT), which integrates eight prominent models regarding the individual acceptance of newly introduced information technologies. In 2003, Venkatesh, Davis and other researchers presented the UTAUT with an attempt to provide further explanation of the user's intention to use the Information Systems and subsequent use behavior. Four main direct determinants of the purpose of utilization are identified in the UTAUT model: performance expectation, effort expectancy, social influences and facilitating conditions, together with another four moderators of the critical relations: gender age, experience and voluntariness.

Adoption follows "direct experience with the technology and after an individual has decided to accept the technology". The implementation of ICT services in developed countries has been studied in several studies, although very little has been achieved in developing countries. Most previous studies are based primarily on theories and models of technological acceptance including the Theory of Reasoned Action (TRA), the Theory of Planned Behavior (TPB), the Technology Acceptance Model (TAM), the Diffusion of Innovation (DOI) and the Unified Theory of Acceptance and Use of Technology (UTAUT), which provide useful insights and implications for understanding an individual's intention of using ICT services, The UTAUT model was lauded for being able to inform the understanding of the factors influencing the adoption of 
a new technology which is imminent. While the model is quite recent, its growth and popularity in comparison with previous versions are increasingly high. Besides, its reliability, validity and feasibility have already been proven and practically validated in several contexts in technology adoption surveys. In 2012, for instance, the Alshehri et al. survey of TAM, TRA and TPM showed that the UTAUT model sheds light on factors that affect the acceptance of critical new technology.

Most of all, over $70 \%$ of the software adoption behavior is clarified by the UTAUT model. UTAUT, therefore, reveals more factors that influence the purpose of the observed behavior. In the end, the inadequacies of previous models and hypotheses were to be remedied by incorporating them for the common good. It has therefore emerged as one of the most comprehensive theories of IT adoption.

Several models in the field of ICT adoption have been used to predict and explain user behavior - the adoption of ICT as a necessary prerequisite for carrying out any ICT project. ICT adoption is considered an essential condition for it; and for an individual's intention to use or adapt an innovation in the present and future in governmental institutions (Díez \& Mclntosh, 2009). The UTAUT is now a mainstream and familiar theory in current ICT literature (Schaupp, Carter, and McBride 2010) and has been cited nearly 5,000 times by Google Scholars. The suitability, validity and reliability of the model were examined in various contexts in technology adoption. The UTAUT model, as it represents a high percentage of the variance of user intent, is said to be a better theoretical than the existing model. (Venkatesh et al., 2003; Al-Shafi \& Weerakkody, 2010). UTAUT offers four fundamental structures: performance expectancy, effort expectancy, social influences, and facilitating conditions (Venkatesh et al., 2003).

This study proposes the following hypothesis and theoretical framework. The theoretical framework posits that social influence has a significant impact on Behavioral intention to use ICT. Furthermore, Behavioral intention has a significant influence on ICT adoption. The following subsections provide descriptions of construct along with the theoretical justification in the theoretical framework and the associated hypotheses.

\section{Social Influence}

In many aspects of the lives of administrative staff in MOHE, social influence is "the degree to which peer influence the use of the system," may it be positive or negative. (Venkatesh et al., 2003). Research shows that administrative staff who use innovation may influence the decisionmaking of others because they believe that innovation will improve their image and reputation or social status. (Fu et al., 2006; Moore and Benbasat 1991; Rogers 2003).

Taiwo and Downe (2013) mentioned that social influence may affect the administrative staff of the ICT through the influence of colleagues and senior management, as they motivate administrative staff to utilize ICT by explaining the benefit and the important to use ICT before and during the use the particular ICT.

Social influence is affecting the plan of the users to use the ICT if other users perceive the importance of ICT as influential to their decision to use and adopt ICT. These kinds of a decision can be influenced by the colleagues who will lead to a positive and negative effect of ICT adoption 
(Daniel, 2015), social influence may influence the users when they see other people using ICT tools as they benefit from it.

This study examined the adoption of ICT administrators and measures the structure for social influence by the perception of how peers influence the use and use of ICT tools by administrative staff. Which is why the researcher proposed this hypothesis:

H1. Social Influence has a positive influence on the administrative staff intentions towards ICT adoption..

H2. Age moderates the influence of social influence on the administrative staff intentions towards ICT adoption.

\section{The Role of Behavioral Intention}

Management scholars believe that the human element is the focus of continuous administrative work, that the word Behavior is generally used in management as in many other areas to denote the forms and patterns of human movement. Behavior refers to the series of successive acts and reactions emanating from the user in his continuous attempts to achieve his goals and satisfy his evolving and changing wishes, as well as acts or responses in which the user expresses acceptance or rejection of attempts to influence the surrounding environment. Whether human or physical, the approach of human relations in the 50s has so far evolved into what is now known as the approach to Behavioral science that tries to link Behavioral science ideas of human Behavior and focuses on processes a scientific analysis of human Behavior to identify how it was originated. The reasons for its formation, and the forms, modes, and means of expression, basic concepts of human Behavior resulting from the successful efforts of scientists constituted a comprehensive logic for understanding Behavior.

Thus, management can influence and modify the Behavior of individuals, human Behavior is determined by social determinants and individual characteristics and under the influence of factors and social and cultural variables.

The behavioral intention of an individual, leading to actual conduct, is, according to TRA, influenced by their subject norm and attitude and is influenced by individual convictions in its attitude. (Ajzen, 1991). Intention means a course of action to be followed and a strong predictor of future conduct. (Zheng et al., 2013). Behavioral intention is the subjective opportunity of an individual to execute specific conduct, and this is important to the actual behavior of the user. (Ajzen, 1985; Fishbein \& Ajzen, 1975; as cited in Lee, 2009). The view of technological adoption is based on the initial intention of the user to use a certain technology. Zhou et al. (2007) stated that the factor affecting the user's intention to adopt and use the technology is to test the users' behavior to use. Abubakar \& Ahmad (2012) indicated that the use of Behavior intention is popular in information technology studies. "Extensions to the various models identified in previous studies mostly enhance the predictive validity of the various models beyond the original specifications" (Venkatesh et al., 2003). Various studies have done, and a series of literature reviews have written on user intention and influential factors on Behavioral intention. 
The behavioral intention measurement included the purpose and forecast use of ICT (Rogers 2003; Venkatesh et al., 2003; Davis 1989). The following hypothesis is proposed to explain behavioral intention.

H3. Behavioral intentions have a positive influence on ICT adoption.

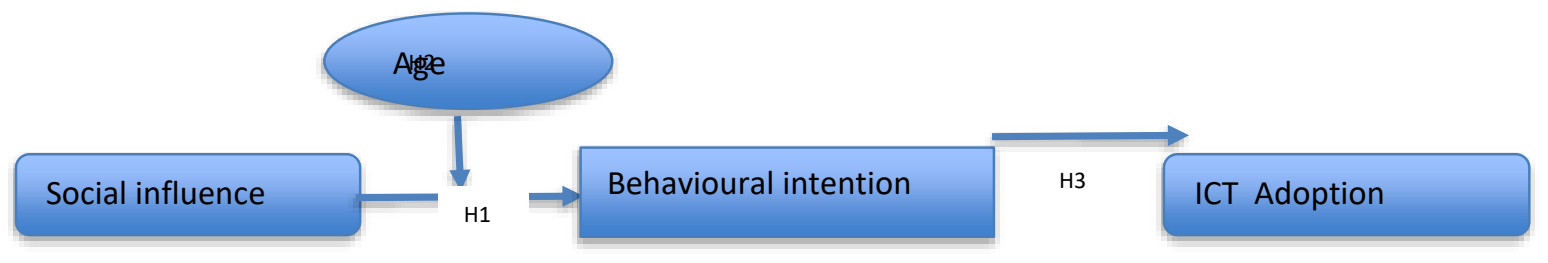

Fig. 1. Study Framework

In light of the problem, objectives, and questions of the study, the researcher used the UTAUT model, which reflects the expected relationships between independent, intermediate and dependent variables in this study. This study is based on the UTAUT model for the adoption and use of ICT, which contains the main determinants of ICT adoption and use, namely; (Performance Expectancy, Effort Expectancy and Social Influence,) based on the original model of Venkatesh et al., (2003).

\section{Methodology}

Sample in research encompasses individuals, events or items that were selected from the population to typically represent the overall population from which the sample was drawn. This study used Palestinian Administrative Staff as interviewees, particularly those serving in the $\mathrm{MOHE}$, are using ICT tools directly. For these reasons, the researcher also chose the MOHE. Firstly, it is the biggest ministry in Palestine, and the staff is having the highest usage of ICT in their daily tasks. Secondly, the MOHE is working hard to develop human resources in the area of education to build highly skilled Palestinian people who can carry out tasks effectively and efficiently.

Targeted population of this study is administrative staffs who make use of the ICT and who have already developed attitudes toward the system operability and effect on the daily activities, staff members such as cleaners, doorkeepers, academics, and teachers who don't deal daily with the system are excluded from the population to become 2370 of administrative staff. Moreover, when the population divided into normal strata and the researcher have the desire to represent all these strata in the sample to pick up sample members from each Job title proportional to its size in population. Table 1 illustrates the distribution of sample size among the Job title and place. According to (Cochran, 1977) the suitable sample size from this population calculated as the following Equation.

$n=\frac{400}{1+\frac{400}{2370}}$ 
Equation 1 Cochran,1977

$$
n=\frac{400}{1.168}=342.46 \approx 343
$$

The Sample size is $=343$, (according to formula in (Cochran, 1977)) +57 (expected loss in questionnaire) $=400$ based on confidence level equal to $95 \%$ and the margin of error of $5 \% "$. The respondents selected for this research are shown in Table 1

Table 1 Sample Size

\begin{tabular}{|c|c|c|c|c|c|c|c|c|}
\hline $\begin{array}{r}\text { Place } \\
\text { job title }\end{array}$ & $\begin{array}{r}\text { Scho } \\
\text { ols }\end{array}$ & $\begin{array}{r}\text { Unive } \\
\text { rsity } \\
\text { colleg } \\
\text { e of } \\
\text { scienc } \\
\text { e and } \\
\text { techn } \\
\text { ology }\end{array}$ & $\begin{array}{r}\text { Minis } \\
\text { try } \\
\text { and } \\
\text { Direct } \\
\text { orate } \\
5\end{array}$ & $\begin{array}{r}\text { Al- } \\
\text { Aqsa } \\
\text { univ } \\
\text { ersit } \\
y\end{array}$ & $\begin{array}{r}\text { Palesti } \\
\text { ne } \\
\text { Techni } \\
\text { cal } \\
\text { Colleg } \\
\text { e }\end{array}$ & Total & $\begin{array}{r}\text { Samp } \\
\text { le }\end{array}$ & $\begin{array}{r}\text { Sampl } \\
\text { e after } \\
\text { roundi } \\
\mathrm{ng}\end{array}$ \\
\hline Secretary & 397 & 16 & 110 & 46 & 17 & 586 & 98.9 & 99 \\
\hline $\begin{array}{r}\text { Administrative } \\
\text { officer }\end{array}$ & & 50 & 533 & 239 & 43 & 865 & 146.0 & 146 \\
\hline Head of the unit & & & 102 & & & 102 & 17.2 & 17 \\
\hline $\begin{array}{l}\text { Head of the } \\
\text { Department }\end{array}$ & & 17 & 213 & 58 & 18 & 306 & 51.6 & 52 \\
\hline School manager & 397 & & & & & 397 & 67.0 & 67 \\
\hline Director & & & 63 & 12 & & 75 & 12.7 & 13 \\
\hline $\begin{array}{ll}\text { Deputy general } \\
\text { director }\end{array}$ & & & 13 & & & 13 & 2.2 & 2 \\
\hline General director & & & 26 & & & 26 & 4.4 & 4 \\
\hline Total & 794 & 83 & 1060 & 355 & 78 & 2370 & 400.0 & 400 \\
\hline
\end{tabular}

SOURCE: Admin Affairs Department, MOHE -Gaza (Jan-2018)

A questionnaire will design to fit the proposed model of this study. Its measuring paragraphs were inspired by instruments used in previous studies as well as the definitions of study model constructs provided in the literature of MIS.

The design of the questionnaire is related to the research questions. When designing the questionnaire and formulating its questions, the researcher must consider two important factors. First, what and how to ask and how these issues are related to each other. The second is, what coding style will be used and what variables and analysis technique that will be implemented. The study instrument will derive its items directly or indirectly from previous studies, which in turn, will ensure the construction validity of the questionnaire. This questionnaire comprised two main parts Part-I covered the demographic traits of the respondent such as gender - age - 
experience - Job title. while part-Il covered the measurement of all study variables. The researcher will use a 7- point- Likert scale, ranging from 1 "strongly disagree" to 7 "strongly agree" (as points 1, 2, 3, 4, 5, 6 and 7, respectively) (Likert, 1932) for all items.

\section{Results}

Table 2 indicates the majority of respondents are males ( 224 or 65.3 per cent) and 158 (46.1 per cent) of respondents are aged between 31 and 40. 123 (35.9\%) respondents served the government for six to ten years. In terms of their experiences. Furthermore, 215 respondents (62.7\%) have a Bachelor's degree as their highest educational qualification, in addition, 145 respondents (42.3\%) their job title was Administrative officer.

Table 2 Demographic Data

\begin{tabular}{llll}
\hline Demographic & Profile & Frequency & Percent \\
\hline Gender & Male & 224 & $65.3 \%$ \\
Female & under20 & 119 & $34.7 \%$ \\
& $20-30$ & 0 & $0 \%$ \\
31-40 & 51 & $14.9 \%$ \\
Experience & $41-50$ & 158 & $46.1 \%$ \\
& above 51 & 84 & $24.5 \%$ \\
less than 5 & 50 & $14.6 \%$ \\
Job title & $6-10$ & 16 & $4.7 \%$ \\
& $11-15$ & 123 & $35.9 \%$ \\
& $16-20$ & 90 & $26.2 \%$ \\
& above 21 & 56 & $16.3 \%$ \\
& Diploma or less & 58 & $16.9 \%$ \\
& Bachelor & 49 & $14.3 \%$ \\
& Master or above & 79 & $62.7 \%$ \\
& Secretary & 64 & $23.0 \%$ \\
& Administrative officer & 145 & $18.7 \%$ \\
& Head of a unit & 16 & $42.3 \%$ \\
& Head of the Department & 46 & $4.7 \%$ \\
& School manager & 53 & $13.4 \%$ \\
& Director & 12 & $15.5 \%$ \\
& Deputy general director & 3 & $3.5 \%$ \\
& General director & 4 & $0.9 \%$ \\
& & & $1.2 \%$ \\
\hline
\end{tabular}

Source: SPSS calculation's

Internal consistency is evaluated by two measures, that are, Composite Reliability (CR) and Cronbach's alpha. CR and the alpha of Cronbach show how much the latent structure appreciates a certain set of manifest variables. However, composite reliability is considered a better internal consistency measure compared with Cronbach's alpha because it uses the standardized loadings 
of the manifest variables. However, the interpretation of Cronbach's Alpha and the composite reliability score is comparable. The value of Cronbach alpha is suggested to be above (0.7) and also to be higher with respect to the composite reliability, 0.7 or higher. (Memon \& Rahman, 2014).

In the current study, all constructs met the minimum requirements; internal consistency was assessed using the composite reliability and Cronbach's alpha. Table 3 shows that the composite reliability values of all variables are acceptable because all of them exceed the minimum requirement of (0.7).

Table 3 Internal Consistency Evaluation (Composite Reliability and Cronbach's Alpha)

\begin{tabular}{llrr}
\hline No. & Constructs & Cronbach's Alpha & \multicolumn{2}{c}{ Composite Reliability } \\
\hline 1 & Social influence & 0.751 & 0.843 \\
2 & Behavioural Intention & 0.868 & 0.896 \\
3 & ICT Adoption & 0.800 & 0.862 \\
\hline
\end{tabular}

Table 4 illustrate that the level of agreement of social influence, Behavioural intention and ICT adoption

Table 4 Summary of results of Model constructs

\begin{tabular}{lllll}
\hline Constructs & N & Mean & Std. Deviation & Result \\
\hline Social Influence & 343 & 5.75 & .651 & Moderately Agree \\
Behavioural Intention & 343 & 6.31 & .624 & Strongly Agree \\
ICT Adoption & 343 & 6.16 & .553 & Strongly Agree \\
\hline
\end{tabular}

The analysis was started depending on the theoretically-based conceptual model of the current study, which had been adapted from the UTAUT theory. Smart-PLS (v3.2.6) was used to test the research model and hypotheses. Smart-PLS is a specialized software package for partial least square structural equation modelling (PLS-SEM). PLS is a regression-based technique that can estimate and test the relationships among constructs through path analysis (Hussein, 2010). PLS path model consists of three components: the structural model, the measurement model and the weighting scheme (Monecke \& Leisch, 2012). PLS specifies relationships in terms of measurement and structural models, which are termed outer and inner models, respectively (Hair et al., 2010)

After running a PLS model, estimates are provided for the path coefficients, which represent the hypothesized relationships linking the latent variables as illustrated in table 5. Path coefficient values are standardized on a range from -1 to +1 , with coefficients closer to +1 representing strong positive relationships and coefficients closer to -1 indicating strong negative relationships. A standard error must be obtained using bootstrapping to test path coefficient values for significance (F. Hair Jr et al., 2014). Bootstrapping is used to test the significance levels of $\beta$ values through the $\mathrm{t}$-value test. The acceptable $\mathrm{t}$ values for a two-tail test are 1.65 (significance level = 10\%), 1.96 (significance level = 5\%), and 2.58 (significance level = 1\%).) (Memon \& Rahman, 
INTERNATIONAL JOURNAL OF ACADEMIC RESEARCH IN BUSINESS AND SOCIAL SCIENCES

Vol. 9, No. 11, November, 2019, E-ISSN: 2222-6990 ㄷ 2019 HRMARS

2014). The present study, re-sampling (bootstrapping, 5000) was used to compute the t-statistic values.

Table 5 Summary of hypotheses (PLS graph) results

\begin{tabular}{rrrrrr}
\hline Hypotheses & Relationship & $\begin{array}{r}\text { Path } \\
\text { Coefficients }\end{array}$ & T-statistics & P Values & Remarks \\
\hline H1 & $\mathrm{SI} \rightarrow \mathrm{BI}$ & 0.202 & $3.516^{* * *}$ & 0.000 & Supported \\
H2 & Age* $\mathrm{SI} \rightarrow \mathrm{BI}$ & -0.159 & $1.865^{*}$ & 0.062 & Supported \\
H3 & $\mathrm{BI} \rightarrow \mathrm{IA}$ & 0.490 & $10.970^{* * *}$ & 0.000 & Supported \\
\hline
\end{tabular}

Note: t-values $>1.65^{*}(p<0.10)$; t-values $>1.96^{* *}(p<0.05)$; t-values $>2.58^{* * *}(p<0.01)$

Effect size $\left(f^{2}\right)$

The $\mathrm{f}^{2}$ is computed by examining the change in the $R^{2}$ value if a specific construct was omitted. To do this, the researcher using the formula of effect size which is complementary to $R^{2}$ (Chin, 2010). The effect size (f2) was calculated as it is not automatically provided in the smart PLS software. The researcher manually calculated it with the help of the formula:

$$
f^{2}=\frac{R^{2} \text { model with mediator }-R^{2} \text { model without mediator }}{1-R^{2} \text { model with mediator }}
$$

Equation 2 Cohen (1988)

The $\mathrm{f} 2$ of an omitted construct can be determined to indicate small, medium and big effects, respectively 0.02, 0.15, and 0.35 for a certain endogenous structure (Hair et al. , 2014), furthermore as recommended by (Cohen, 1988).

Table 6 Effect size $\left(\mathrm{f}^{2}\right)$ of Hypotheses

\begin{tabular}{llllllll}
\hline Hypotheses & $\mathbf{f}^{\mathbf{2}}$ & Mean & $\begin{array}{l}\text { Standard } \\
\text { Deviation }\end{array}$ & $\begin{array}{l}\mathbf{T} \\
\text { Statistics }\end{array}$ & $\begin{array}{l}\mathbf{P} \\
\text { Value } \\
\mathbf{s}\end{array}$ & $\begin{array}{l}\text { Effect size } \\
\text { Rating }\end{array}$ & Effect \\
\hline $\mathbf{H}$ : $\mathbf{S I} \rightarrow \mathbf{B I}$ & 0.202 & 0.203 & 0.057 & 3.516 & 0.000 & medium effect & Indirect \\
$\mathbf{H 3}: \mathbf{B I} \rightarrow$ IA & 0.490 & 0.490 & 0.045 & 10.970 & 0.000 & large effect & \\
\hline SI $\rightarrow$ IA & 0.099 & 0.100 & 0.031 & 3.168 & 0.002 & small effect & Direct \\
\hline
\end{tabular}


The result of hypothesis testing indicated that the mediating effect of Behavioral intention on the relationship between social influence and ICT adoption is varied. However, to get more details of these relationships researcher presents the hypothesis in this study by a line graph. Age of Social Influence and Behavioral Intention In Figure 2, there are two different curves in the relationship between Social Influence and Behavioral Intention, Moreover, Table 5 supports the moderating effect of Age on the relationship between social and Behavioral influences. Figure 2 also confirmed this result. It can be concluded that there was a significant difference between curves of high and low-level Age in the relationship between Social Influence and Behavioral Intention. In other words, Age dampens the positive relationship between Social Influence and Behavioral Intention to adopt ICT in MOHE in Palestine.

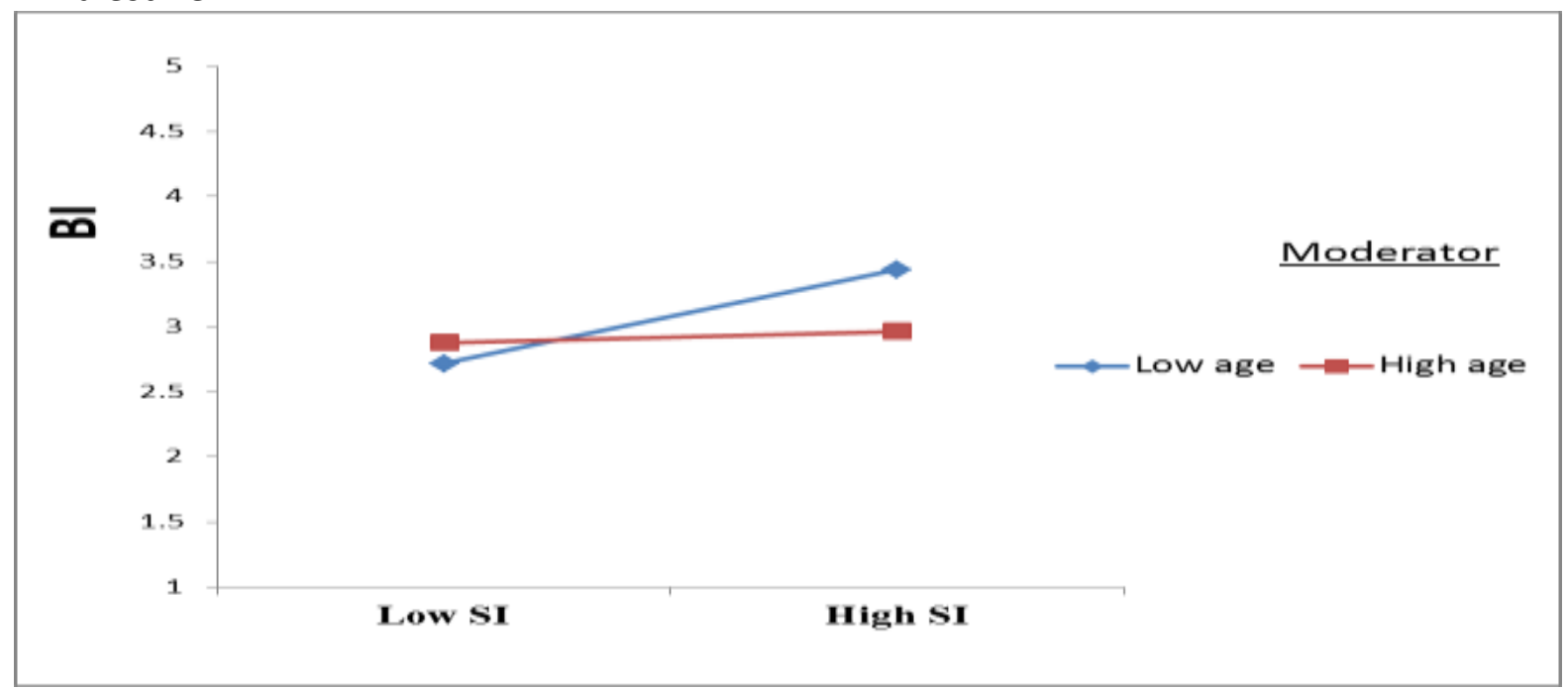

Figure 2 The moderating effect of Age on Social Influence and Behavioural Intention

As shown in table 5 and table 6 the results of PLS analysis present empirical support for Hypotheses $\mathrm{H} 1, \mathrm{H} 2, \mathrm{H} 3$. The paths $\mathrm{H} 1$ : $\mathrm{SI} \rightarrow \mathrm{BI}(\beta=0.202, p<0.05)$ and suggests that there is a positive significant impact from the factors (social influence) on the "Behavioural Intention ". In addition, $\mathrm{H3}: \mathrm{BI} \rightarrow \mathrm{IA}(\beta=0.490, p<0.05)$ shows that the impact is significant from Behavioural Intention on the "ICT Adoption ". As noted from the $\beta$ coefficient the relationship is positive for all factors. Moreover, the results showed that there is a negative impact from the paths $\mathrm{H} 2$ : Age* $\mathrm{SI} \rightarrow \mathrm{BI}$ moderated by Age $(\beta=-0.159, \mathrm{p}<0.05)$.

In addition, the computed effect size values $\left(\mathrm{f}^{2}\right)$, which are presented in table 6 , refer to large effect size for hypotheses H3. On the other hand, the effect size values of the hypotheses $\mathrm{H} 1$ is medium effect. Hence, it can be concluded from these values that the impact of Social Influence (SI) on Behavioral Intention (BI) is the medium effect. Moreover, the effect size results refer to a large effect of Behavioral Intention (BI) on ICT Adoption (IA), In addition, the direct impact of Social Impact (SI) on ICT Adoption (IA) is noted in Table 6 as being small. The researcher refers this for the fact that a large proportion of the study sample is 95 per cent whose working 
experience is more than six years; thus, it is easy for the low level of experience to copy the Behavior from a high level of experience towards adopting ICT in their administrative transaction. Also, the majority of the sample of the study are holders of bachelor's degrees or above which constitute about 86 per cent of the total sample of the study. Therefore, it was easy for them to understand, comprehend and adopt ICT in the MOHE in Palestine. This again suggests the strength of the model in explaining the variation of the "Behavioral Intention" and the "ICT adoption" variables. It highlights the effect of the external factors "Social Influence" on "Behavioral Intention ". It also highlights the effect of the mediating role of Behavioral Intention on "ICT adoption".

\section{Conclusion}

This study measures the role of age as a moderator in the relationship between social influence and behavioral intent, and it measures Administrative Staff Behavioral Intention as a mediator on ICT adoption at MOHE in Palestine. The study showed that MOHE administrative staff are highly inclined to accept ICT in their daily work. Moreover, social influence positively affects the Behavioral intention of ICT adoption in MOHE, and the age negatively moderates the relation between social influence and Behavioral intention. This study examined the role of mediating in the relationship between the independent variable and the dependent variable of the Behavioral intention. The findings have shown that Behavioral intention has a positive effect on the social impact of ICT adoption in MOHE.

This study is, however, one of the few studies on ICT adoptions based on UTAUT theory carried out particularly in the Arab countries. The findings can serve as guidelines in increasing ICT adoption and thus increase the quality of services in developing countries. Also, the findings from this research can provide information to supply-side in a better understanding of users' needs and how to increase user's retention in using ICT.

This study thus contributes to the expansion of ICT adoption research by adding the Arab viewpoint.

This is significant in permitting a test of wider validity of findings derived from studies conducted in developing countries with experience in the context of the ICT adoption. In general, most of the administrative staff agreed that there is a relationship between social influence and behavioral intention towards ICT adoption. As well as, social influence are related positively to behavioral intention towards ICT adoption.

In regard of the managerial perspective, findings from this study can also yield several significant insights for ICT adoption design and usage strategy. The organization's top management should be aware that the intangible benefits of ICT, especially at its early stages. It is common that such intangible outcome consumes a long time to be transformed into tangible benefits and thus usually underestimated by the top management. Therefore, all benefits, tangible and intangible, should be comprised in the ICT return on investment analysis. In addition, top management should increase the awareness of MOHE management and administrative staff about the importance of ICT and its great role in raising the organization's value. In addition, it is advisable to promote human resources department to enhance and develop administrative staff and 
manager's capabilities and skills through enhancing training process which has an important role in improving administrative staff practical skills in the ICT adoption.

However, there were several limitations to this study. First, only the MOHE servants in Palestine included the study respondents. Future research should include respondents from other ministries of government, as the ICT applied throughout the ministries of government. Secondly, the study used the data collection questionnaire only. Interviews to enable respondents to express their opinion on ICT adoption and use could be used to collect more meaningfully. The reason for this lies in the fact that interviews can offer a closer look at the questions posed and that the investigator may take the opportunity of clarifying any doubts.

\section{References}

Abubakar, F. M., \& Ahmad, H. (2012). Determinants of Behavioural Intention to Use E-Payment System in Nigerian Retail Industry: A ConceptualExtension of UTAUT with Concern for Customers, 1(1), 87-93.

Ajzen, I. (1991). The theory of planned behaviour. Organizational Behaviour and Human Decision Processes, 50(2), 179-211.

Al-Hujran, O., Al-debei, M. M., Chatfield, A., \& Migdadi, M. (2015). The imperative of influencing citizen attitude toward e-government adoption and use. Computers in Human Behaviour, 53, 189-203. https://doi.org/10.1016/j.chb.2015.06.025

Al-Shafi, S., \& Weerakkody, V. (2010). Factors affecting e-government adoption in the state of Qatar. Proceedings of the European and Mediterranean Conference on Information Systems Abu Dhabi UAE 1213 April 2010, 2010, 1-23. https://doi.org/10.1179/204264411X12961227987886

Alawadhi, S., \& Morris, A. (2008). The Use of the UTAUT Model in the Adoption of E-government Services in Kuwait. In Proceedings of the 41st Hawaii International Conference on System Sciences (pp. 1-11).

Aleke, B., Ojiako, U., Wainwright, D. W., Aleke, B., \& Wainwright, D. W. (2011). ICT adoption in developing countries : perspectives from small-scale agribusinesses. Journal of Enterprise Information Management, 24(1), 68-84. https://doi.org/10.1108/17410391111097438

Alshehri, M., Drew, S., \& Alghamdi, R. (2012). E-Government Services : Applying the Utaut Model. In IDIAS international conference theory and practice in modern computing and internet application and research (pp. 69-76).

Attuquayefio, NiiBoi, S. H. A. (2014). Using the UTAUT model to analyze students' ICT adoption Samuel NiiBoi Attuquayefio Methodist University College, Ghana Hillar Addo University of Professional Studies, Ghana. International Journal of Education and Development Using Information and Communication Technology (IJEDICT), 10(3), 75-86. 
Ayyash, M. M., Ahmad, K., \& Singh, D. (2013). Investigating the effect of information systems factors on trust in e-government initiative adoption in palestinian public sector. Research Journal of Applied Sciences, Engineering and Technology. Vol. 5. No. 15. pp. 3865-3875.

Belanche-Gracia, D., Casaló-Ariño, L. V., \& Pérez-Rueda, A. (2015). Determinants of multi-service smartcard success for smart cities development: A study based on citizens' privacy and security perceptions. Government Information Quarterly, 32(2), 154-163. https://doi.org/10.1016/j.giq.2014.12.004

Chen, M., Zhang, D., \& Zhou, L. (2007). Empowering collaborative commerce with Web services enabled business process management systems, 43, 530-546. https://doi.org/10.1016/j.dss.2005.05.014

Cochran, W. G. (1977). Sampling Techniques. 3rd Edition. John Wiley and Sons.

Davis, F. D. (1989). Perceived Usefulness, Perceived Ease of Use, and User Acceptance of Information Technology. MIS Quarterly, 13(3), 319-340.

Díez, E., \& Mclntosh, B. S. (2009). A review of the factors which influence the use and usefulness of information systems. Environmental Modelling and Software, 24(5), 588-602. https://doi.org/10.1016/j.envsoft.2008.10.009

Fouad, J. F., Shat, A. M., \& E. P. (2014). Electronic Government Enactment in a Small Developing Country - the Palestinian Authority's Policy and Practice. Communications in Computer and Information Science. Vol. 441. No. 3. pp. 83-92.

Gallego, J. M., Gutiérrez, L. H., \& Lee, S. H. (2011). A Firm-Level Analysis of ICT Adoption in an Emerging Economy : Evidence from the Colombian Manufacturing Industries, (116).

Gupta, B., Dasgupta, S., \& Gupta, A. (2008). Adoption of ICT in a government organization in a developing country: An empirical study. Journal of Strategic Information Systems, 17(2008), 140-154. https://doi.org/10.1016/j.jsis.2007.12.004

Hair, J. J. F., Hult, G. T. M., Ringle, C. M., \& Sarstedt, M. (2017). A primer on partial least squares structural equation modelling (PLS-SEM). 2nd Edn., USA: Sage.

Hair, J. F., Black, W. C. \& Babin, B. J. (2010). Multivariate data analysis: A global perspective. Pearson Education, Limited.

Hung, M., Chang, I., \& Hwang, H. (2011). Computers \& Education exploring academic teachers' continuance toward the web-based learning system: The role of causal attributions. Computers \& Education, 57(2), 1530-1543.

https://doi.org/10.1016/j.compedu.2011.02.001

Hussein, S. A. (2010). An empirical investigation of information systems success. An analysis of the factors affecting banking information systems success in Egypt. The University of Bradford.

Hwang, H. G., Chang, I. C., Chen, F. J., \& Wu, S. Y. (2008). Investigation of the application of KMS for disease classifications: A study in a Taiwanese hospital. Expert Systems with Applications, 34(1), 725-733. https://doi.org/10.1016/j.eswa.2006.10.018

Lancaster, G. A., Dodd, S., \& Williamson, P. R. (2004). Design and analysis of pilot studies: Recommendations for good practice. Journal of Evaluation in Clinical Practice, 10(2): 307312. Available at: https://doi.org/10.1111/j..2002.384.doc.x. 
Lee, M. C. (2009). Factors influencing the adoption of internet banking: An integration of TAM and TPB with perceived risk and perceived benefit. Electronic Commerce Research and Applications, 8, 130-141.

Likert, R. (1932). A technique for the measurement of attitudes. Archives of Psychology 140.

Memon, A. H., \& Rahman, I. A. (2014). SEM-PLS analysis of inhibiting factors of cost performance for large construction projects in Malaysia: a perspective of clients and consultants. The Scientific World Journal, 2014.

Monecke, A., \& Leisch, F. (2012). semPLS: structural equation modelling using partial least squares.

Nugroho, R. A. (2015). Electronic Government Adoption in Developing Countries: The Case of the Indonesian Electronic Procurement System. University of Queensland, 1-192. Retrieved from https://espace.library.uq.edu.au/view/UQ:371615/s42148386_phd_submission.pdf

Oliveira, T., Martins, M. F., \& Lisboa, U. N. D. (2011). Literature Review of Information Technology Adoption Models at Firm Level. Electronic Journal of Information Systems Evaluation, 14(1), 110-121.

Schaupp, L. C., Carter, L., \& McBride, M. E. (2010). E-file adoption: A study of US taxpayers' intentions. Computers in Human Behaviour 26 (4):636-44. DOI:10.1016/j.chb. 2009.12.017

Sekaran, U., and Bougie, R. (2010). Research methods for business: A skill-building approach. 5th Edn., West Sussex, UK: John Wiley \& Sons Ltd.

Shehry, A. A. L., Rogerson, S., Fairweather, N., Ben, \& Prior, M. (2009). The Key Organisational Issues Affecting E-Government Adoption in Saudi Arabia. International Journal of Electronic Government Research (IJEGR), 5(4), 1-13. https://doi.org/10.4018/jegr.2009070201

Sirirak, S., Islam, N., \& Khang, D. B. (2005). Does ICT adoption enhance hotel performance ? Journal of Hospitality and Tourism Technology, 2(2011), 43-49. https://doi.org/10.1108/17579881111112403

Taiwo, A. A., \& Downe, A. G. (2013). The theory of user acceptance and use of technology (UTAUT): a meta-analytic review of empirical findings. Journal of Theoretical and Applied Information Technology. 49(1): 48-58.

Teijlingen, V. E. R., Rennie, A. M., Hundley, V., and Graham, W. (2001). The importance of conducting and reporting pilot studies: The example of the Scottish Births survey. Journal of Advanced Nursing, 34(3): 289-295. Available at: https://doi.org/10.1046/j.13652648.2001.01757.x.

Venkatesh, V., Michael, G., Morris, G. B., Davis, F. D. D. (2003). User Acceptance of Information Technology : Toward a Unified View. MIS Quarterly, 27(3), 425-478.

Zheng, Y., Zhao, K., \& Stylianou, A. (2013). The impacts of information quality and system quality on users' continuance intention in information-exchange virtual communities: An empirical investigation. Decision Support Systems, 56(1), 513-524. https://doi.org/10.1016/j.dss.2012.11.008 